\title{
Consultation Phases in Mathematics Learning and Support Centres
}

\author{
Mirko Schürmann ${ }^{1}$ D Anja Panse ${ }^{1} \cdot$ Zain Shaikh $^{2} \cdot$ Rolf Biehler $^{1}$. \\ Niclas Schaper ${ }^{1} \cdot$ Michael Liebendörfer $^{1} \cdot$ Joachim Hilgert ${ }^{1}$
}

Accepted: 21 July 2021 /Published online: 20 August 2021

(c) The Author(s) 2021

\begin{abstract}
Mathematics Learning Support Centres are becoming more and more common in higher education both internationally and in Germany. Whereas it is clear that their quality largely depends on a functioning interaction in consultations, little is known about how such consultations proceed in detail. On the basis of models from the literature and recorded support sessions $(\mathrm{N}=36)$, we constructed a process model that divides consultations into four ideal-typical phases. In the individual consultations, forward or backward leaps occur, but overall the model seems to describe the data well. A high intercoder reliability shows that it can be applied consistently on real data by different researchers. An analysis of the consultations between students and tutors shows that both mainly work on past attempts or thoughts of the students to solve the exercise or problems and on concrete strategies to solve a problem within the session. In contrast, very little time is dedicated to summarizing and reflecting the solution. The data allows for a more in-depth discussion of what constitutes quality in advising processes and how it might be further explored. Practically, the model may structure support sessions and help in focussing on different goals in different phases.
\end{abstract}

Keywords Mathematics learning support · Consultation · Phase model · Interaction · Speech time

Mirko Schürmann

mirko.schuermann@upb.de

1 University of Paderborn, Paderborn, Germany

2 Berlin, Germany 


\section{Introduction}

Many students face great challenges learning mathematics in higher education, especially at the beginning of their studies. Subjects containing mathematics have the highest dropout rates in Germany (Heublein \& Schmelzer, 2018), According to Heublein et al. (2010), the main reasons are demanding study and examination requirements, so "that many students cannot cope with without appropriate supervision and support" (p.153). We focus on students enrolled in mathematics programs as well as specific programs for higher secondary teachers. In these programs, dropout rates are estimated to be as high as 80\% (Dieter \& Törner, 2012). Students from both programs traditionally attend the same courses at the beginning of their studies, namely courses on linear algebra and calculus.

A typical mathematics course at a German university consists of lectures and additional tutorials. Mostly the content is presented to the students by the professor within lectures whereas tutorials are run by tutors. A main focus of students' work is on weekly exercises set by the professors. Students are expected to work on both the compulsory exercises and the lecture contents outside the tutorials. The exercises are often the starting point for students' self-organized learning (Göller, 2020) and they are central to the stress and pressure many students experience (Liebendörfer \& Hochmuth, 2017). Mostly, these assignments must be submitted individually but sometimes submission in pairs is allowed. It is not allowed but well known and common that students share and copy (some of) their solutions (Liebendörfer \& Göller, 2016). Many students have substantial problems in understanding the lectures and solving the tasks.

In response to students' struggle, many Mathematics Learning and Support Centres (MLSCs) were established in Germany in the last decade. MLSCs in Germany can be described as a low-threshold support offered to students in a specific site on campus (not an office) in addition to the curriculum. In the MLSCs, advice and support are offered to students on mathematical topics and tasks. Students also use the MLSC as an additional learning environment to work on mathematical study assignments by themselves or in learning groups (Hochmuth et al., 2018). Just now 61 MLSCs with focus on mathematic support and 16 additional MLSCs focusing on support for mathematics didactics exist in Germany (Schürmann et al., 2020).

In many English-speaking countries (such as the UK, Ireland, Australia, USA), MLSCs are well implemented and evaluated (Grove et al., 2019b; Lawson et al., 2019; Mills et al., 2020). Within a MLSC, support is often offered by tutors. In Germany, $47.5 \%$ of the MLSCs employ tutors (under- or postgraduate students) and only in $11.9 \%$ support is given by academic staff only. In $40.7 \%$ of all MLSCs a mix of both groups is employed (Schürmann et al., 2020). Grove and colleagues (2019b) aggregated their findings and showed that in the UK and Ireland most MLSCs are run by part- or full-time staff (78\%) whereas post- or undergraduate tutors are less common $(46 \%, 26 \%$ respectively). Within a national survey in the USA (Johnson \& Hanson, 2015) the result showed that in most mathematic tutoring centres undergraduates $(87 \%)$ were common staff followed by graduate students $(33 \%)$ and professional staff $(27 \%)$ or faculty members $(30 \%)$. So tutors 
play an important role in MLSCs as mixed teams of part- or full-time staff give support in their role as managers and pre- or postgraduate students in their role as tutors in most MLSCs. Grove et al. (2019c) emphasise the important role of tutors within Mathematic Learning Support Centres (MLSC) especially when it comes to tutor and student interactions. The crucial role of MLSC tutors in students' success "reflects the unique MLS[C] student-tutor relationship where oneto-one support is provided in a relaxed and non-threatening environment" (Grove et al., 2019c, p.4). In context of analysing the role of staff members Grove and colleagues conclude, "Tutors, be they members of staff or postgraduate students, are vital to the success of mathematics support" (Grove et al., 2019a, p.57).

There is, however, little knowledge on how tutors and students interact. We thus aim for a more detailed description on how support sessions work. Knowing more about how a typical support session works could be helpful for everyone involved: students might more easily engage in a visit to a MLSC if they knew what happened there. Perhaps more tutors could be recruited as well and they might want to reflect on their sessions. Centre managers could better target tutor trainings. Finally, lecturers could better coordinate the different support measures and feel more comfortable giving some responsibility for teaching into tutors' hands. In the long-term students should benefit from a better MLSC support and improvement of their learning (outcomes). We therefore aim at a description of the typical structure of support sessions.

\section{Mathematical Learning and Support at the University of Paderborn}

To support students in mathematics major and higher secondary teacher programs, especially in the crucial study entry phase, the University of Paderborn (UPB) offers three different forms of Mathematics Learning Support (MLS): pre-university bridging courses, bridging lecture courses for first semester students and mathematics learning and support centres. The first, pre-university mathematical bridging courses are offered to students before they start their studies (Fleischmann \& Kempen, in press; Bausch et al., 2014; Fischer, 2014). They aim to bridge the gap between school mathematics and higher mathematics as well as to introduce students to their study programs and form working skills (Biehler et al., 2018). One particular bridging course for the preservice higher secondary teachers in the first semester was implemented in 2012 as a lecture (Panse et al., 2018). Since 2011, a MLSC called Lernzentrum complements this set of support means at UPB for mathematics students and preservice higher secondary teachers (Panse et al., 2018).

The MLSC is located in a dedicated room where students can study in groups (or alone), with a student assistant (SA) who works as a tutor. During drop-in service hours (35.5 h/week), tutors help students with mathematics related questions. There are ten to twelve tutors in the Lernzentrum every semester along with two academic staff members. All tutors work mainly within the specific mathematics tutorials, in which the content of the regular mathematics lectures is examined more closely. For these tutorials, the tutors have been qualified by specific trainings offered by the university. They consist of a one-day workshop, peer internships and reflection meetings. For the work within the Lernzentrum, tutors are additionally trained within a 
workshop (half a day) and instructed by the managers as well as by experienced MLSC tutors. Traditionally, all tutors are students from the mathematics study program at UPB and must have passed tutorial-related modules sufficiently. The MLSC service hours are scheduled according to the tutors' mathematical competences and specialities. For example, if a student needs help in linear algebra, he/she can go to the Lernzentrum during the time slot allotted to the linear algebra tutor and ask for support. These content-specific service hours are not exclusive, so students with problems from other mathematics courses are welcome as well. Many students use the Lernzentrum as a study room for different mathematics courses and still ask the tutors for help on topics that may not be their specialty. In addition to the dropin service, the Lernzentrum offers workshops and special support activities during examination phases as well as a variety of learning materials.

\section{Empirical Background and Theoretical Framework}

We define a mathematical learning and support centre (MLSC) as low-threshold and extracurricular support for students, where, employees (academic staff or tutors) offer advice and support to students on mathematical topics and tasks. Students also use the MLSC as an additional learning environment to work on their mathematical study assignments by themselves or in learning groups (Hochmuth et al., 2018). This definition is consistent with definitions given by others. Lawson et al. (2003) defined Mathematics Support Centre (MSC) as "a facility offered to students (not necessarily of mathematics) which is in addition to their regular program of teaching through lectures, tutorials, seminars, problems classes, personal tutorials, etc." (p. 9). They recommend to use the term widely "encompassing a wide range of provision (known in different institutions by various names including Maths Workshop, Maths Help, Maths Drop-In)" (Lawson et al., 2003, p. 9). Lately, Lawson et al. (2019) pointed out that there are two dominant forms of mathematics support centres "the drop-in centre and the bookable one-to-one appointment" (p. 1). Within this article we stick to the MLSCs definition above to emphasise the aspect of mathematics support centres as a learning environment.

From an international perspective, research on MLSC or MSC has yielded a diversity of findings. A summary of those has been published in two major literature reviews, one by Matthews et al. (2013) and one by Lawson et al. (2019). They reviewed research from publications in the UK, Ireland and Australia. Matthews et al. (2013) summarized findings on research evidencing the prevalence of mathematics support, the aims and definitions of mathematics support centres, the forms of MSC evaluations and evidence of their effectiveness. Lawson et al. (2019) focussed on main themes emerging from their review:

- characteristics of users and non-users of mathematics support,

- role of the mathematics support tutors and their training,

- positioning of mathematics support within higher education structures and

- evaluation of the effectiveness of mathematics support. 
In Germany, only little research on MLSCs has been published. Most publications on MLSCs focus on the description of concepts of one centre, their experiences or present their student evaluation results (e.g. Frischemeier et al., 2016; Milfeit et al., 2018; Panse et al., 2018; Wlassak, 2018). In the research project WiGeMath, ${ }^{1}$ an overview on prevalence of MLSCs in Germany and their main characteristics was published (Schürmann et al., 2020) and systematic evaluations on six German MLSCs were conducted (Hochmuth et al., 2018). The MLSCs in Germany vary according to the type of higher education institution at which they are anchored, in terms of the qualifications and size of the staff, and the opening and supervision times. Conceptually, mathematical learning centres particularly differ in the qualifications of their staff who offer individual advice. As mentioned above, learning centres employ student assistants as tutors for the support, employ academic staff or use both groups for the support (Schürmann et al., 2020). Overall, the results of the WiGeMath project show a positive assessment of the six MLSCs, the respective framework conditions and the quality in general, and in particular of the support given to students, by either tutors or academic staff (Hochmuth et al., 2018). MLSCs seem to be attended by many students and were positively evaluated especially for the low-threshold level of support and the easy access for students. All MLSCs were drop-in centres by definition. The student surveys showed, for example, that students rate the support of either tutors or staff and team as very helpful and an expansion of the range of services was repeatedly requested (Hochmuth et al., 2018). These findings equal the results of international research. For example, O'Sullivan et al. (2014) present an evaluation of nine Irish MLSCs based on the views of 1633 first year students. They point out the impact which mathematics learning support centres [these authors use the abbreviation MLS for mathematics learning support centres] can have on learners as:

$22 \%$ of respondents who had availed of MLS had considered dropping out of their course due to mathematical difficulties and almost two thirds of these students stated that availing of MLS had a positive impact on their retention on their course (O'Sullivan et al., 2014, p. 11).

\section{The Role of Tutors in MLSCs}

In higher education the role of tutors has become increasingly important in recent years. As in Germany and in many other countries, traditional lectures are complimented by tutorials taught by either undergraduate or graduate tutors. The role of tutors within the tutorials has been described and researched (MacDonald, 2000; Püschl, 2017, 2019; Walsh, 2017).

\footnotetext{
${ }^{1}$ 1. WiGeMath stands for "Wirkung und Gelingensbedingungen von Unterstützungsmaßnahmen für mathematikbezogenes Lernen in der Studieneingangsphase"; "Effects and success conditions of mathematics learning support in the introductory study phase". It is a joint research project of the Universities of Hannover and Paderborn that operated from 2015 through 2018 and was followed by WiGeMath-Transfer operating until 2020.
} 
The roles of tutors working in MLSC are slightly different. The focus lies on oneto-one support initiated by the students' problems which tutors can hardly predict and the contents are not as foreseeable as in tutorials.

As described by Lawson et al. (2019), tutors play a key role in the MLSCs as they are the ones mainly interacting with the students. Within their review, they highlight the important role of tutors, the tasks and demands they are confronted with during student interactions and in their relationship to them.

Additionally, tutors usually have no prior knowledge of the questions they are likely to be asked. Consequently, they must be able to think on their feet and be willing to explore and research possible solutions in partnership with the student seeking help. They must try to understand the student's mathematical problems and then offer guidance, motivation and support to help the student successfully work through their issues (Lawson et al., 2019, p.13).

This is a complex job and tutors may undergo a substantial development that may contribute to successful support sessions. This may include, for example, focusing on giving help instead of solving the problem under consideration themselves or adapting to the students' knowledge and background (Grove \& Croft, 2019). To cover these different tasks and demands, tutors need to be trained and qualified. Different articles highlight the importance of tutor trainings (e.g. Croft \& Grove, 2016; Grove et al., 2019c; Lawson et al., 2019; O'Sullivan et al., 2014; Pfeiffer et al., 2016). Croft and Grove (2011) published a training guide for postgraduate students working in MLSCs which, among other things, gives information about dos and don'ts, advice to problem solving issues and the special demands which occur in statistics support as well as the importance of being aware of individual differences and needs of students. They used their experience from tutor training workshops within the sigma network (Croft et al., 2015) to write this guide and then provided material and information for free use in any further tutor qualification workshops. Grove and colleagues (2019c) present a concept for professional development opportunities for tutors of mathematics learning support, describing the "sigma tutor training workshop" based on Croft and Grove (2011) and a workshop concept run within the Irish Mathematic Support Network. They further present and discuss opportunities of accreditation of these trainings as micro-credentials.

Each micro-credential contains a description of the abilities which the tutor must develop and a description of the evidence that they must provide to show that they have demonstrated these abilities. The micro-credentials have been designed to equate to 5 ECTs postgraduate credits once all four have been completed (Grove et al., 2019c, p.13).

In Germany, no detailed training concept for tutors' MLSC qualification has been published yet. During the study within the WiGeMath-Project, we found five out of six participating MLSCs having trainings for MLSC tutors. These vary from informal elaborated instructions and guidelines to intensive one- or two-day training workshops. All trainings share the principle not to give solutions for study tasks or assignments to the students. Most MLSCs trainings, including our own at UPB, stick to the 
didactical principle of minimum help [minimale Hilfe] (Aebli, 2006) or the stepwise helping approach [gestufte Hilfe] by Zech (1996) when support is given to students by tutors (s.f. descriptions Kaiser \& Ständer, 2013; Greefrath \& Vorhölter, 2016). This is consistent with the training concept provided by sigma network mentioned above, in which tutors' potential behaviour is described by do's and don'ts and in a practical manner how tutors can support students with mathematical problem solving. In none of these training concepts is a description of typical consultation phases included.

Whereas some ideas exist on what defines high quality support, we do not know how this support in MLSCs is given in practice and in detail. Grove and Croft (2019, p. 263) conclude, that "very little is known about the practices of tutors in a support centre and how they interact with students". In particular, there is a lack of observational studies which analyse student and tutor interactions and their communication.

\section{Models for the Tutor-Student Interaction}

The interaction between tutors and students within mathematics higher education has been described and analysed mostly in the context of tutorials. Schoenfeld and colleagues (1992) presented a comprehensive model of human tutoring which grounded on the data analysis of four videotaped sessions along with pre- and posttests. The model tries to explain tutor behaviour within a goal driven structure which is aligned to the curriculum and influenced by tutor's pedagogical und individual tendencies as well as the tutor's sense of the domain and what the student understands. Later, Schoenfeld (2010) published his theory of goal-oriented decisionmaking and its educational applications, which can also be used to analyse and describe teaching or tutoring behaviour (Schoenfeld, 2015). Recently, Burks and James (2019) presented a schema for mathematical knowledge for tutors in undergraduate study programs based on Ball et al.'s (2008) Mathematical Knowledge for Teaching framework and expanded by the dimensions of affect and self-regulation. Burks and James (2019) propose that their framework "will help guide the focus of qualitative analysis of tutor actions and interactions" (p.732). The Tutor Circle by MacDonald (2000) is prominent in the USA and Canada and is used for trainings of tutors and addresses different steps in a tutorial. These frameworks and theories mentioned above are important and useful in terms of tutor qualification and research on tutor behaviour. However, they lack information on how interactions between tutors and students can be described or analysed when these are driven by the individual demands of the students within a MLSC.

Similar to Schoenfeld's (1992) division of tutorials into three different phases of conversation, we sought phase models to analyse and describe the communicative interactions within MLSCs in more detail. As we found no phase model which is specific for MLSC consultations or other mathematics related consultations, we looked for phase models from other disciplines.

In Germany, models for consultation in higher education and in other fields exist. A summary of these models is provided by Gieseke et al. (2007) and Gieseke and Stimm (2016). We refer to some of these and describe four different models [own translations], 
which might be useful for educational counselling of students (c.f. Table 1). These models were set up to describe counselling processes in different fields.

The first model by Bauer (1991) was set up in the context of vocational education for training advices to clients and higher education. He proposed 4 phases of a consultation process which can be characterized by steps of action. In phase (1), the articulation of the consulting reasons and the clients' problems should be focussed and clients should talk about their needs and motives as well as their concrete wishes on training activities. In phase (2), a common analysis as well as a thematization of a problem structure is recommended. Consultants should help their clients in their process of decision making (e.g. analyse dependencies for decisions). In phase (3), information and advice is given to the client on how to solve the problem. The consultant should give a perspective on new aims, describe ways to achieve them, change client's motivation and correct unrealistic expectations. In phase (4), the consultant gives assistance on changes of the problematic situation and concrete advice for training activities and next steps.

The second model by Just-Nietfeld and Nickels (2006) describes three phases of general student counselling in higher education. In the opening phase (1), a relationship between student and consultant is built up and concerns of students should be clarified. It is recommended to use conversational methods in this phase which encourage students to open up and to present their concerns in detail. In the processing phase (2), the students' concerns or problems should be explored by questions and the consultant should analyse the students' situation and behaviour. In the closing phase (3), information is given to students and they together with the consultants should develop plans for further action.

The third model by Thiel (2003) for pedagogical consultations consists of seven phases. This model differs from those presented above. Thiel (2003) proposes to start with an analysis or description of the problem on the "IS situation", in which students should for example describe their situation and competences (1). In the next step, this is contrasted to the AIM state (2) where aims are clarified and intermediate as well as final aims are set. Different ways to achieve the aim are content of phase (3) and measures of the achievement are presented by the consultant. After this, a decision (4) has to be made which way-aim-relation the students want to follow. The next steps, planning an implementation (5) and the participation of the students in a measure (6), as well as control and measurement of results (7), go beyond the models described above and include evaluation aspects which might not be typical for consultations.

The fourth model of Pantucek (1998) describes phases in a counselling process of social workers with a special focus on tenses to be used in the conversations in each phase. Initially, the model was set up to anchor different techniques of conversations. He advices to start with an introduction (1), to do small-talk and give the client a warm welcome. This conversation should be done in present tense. In the exploration phase of the client's problems (2), the consultant should focus on active listening, asking questions and helping in formulating goals. Here, conversation should be made in past or present tense. In the construction phase (3), the consultant informs the clients about different ways to goal achievement, next steps should be negotiated and scheduled. The special time focus here lies on nearer future. In the contracting phase (4), further plans are developed with the clients and appointments are made. Conversations 


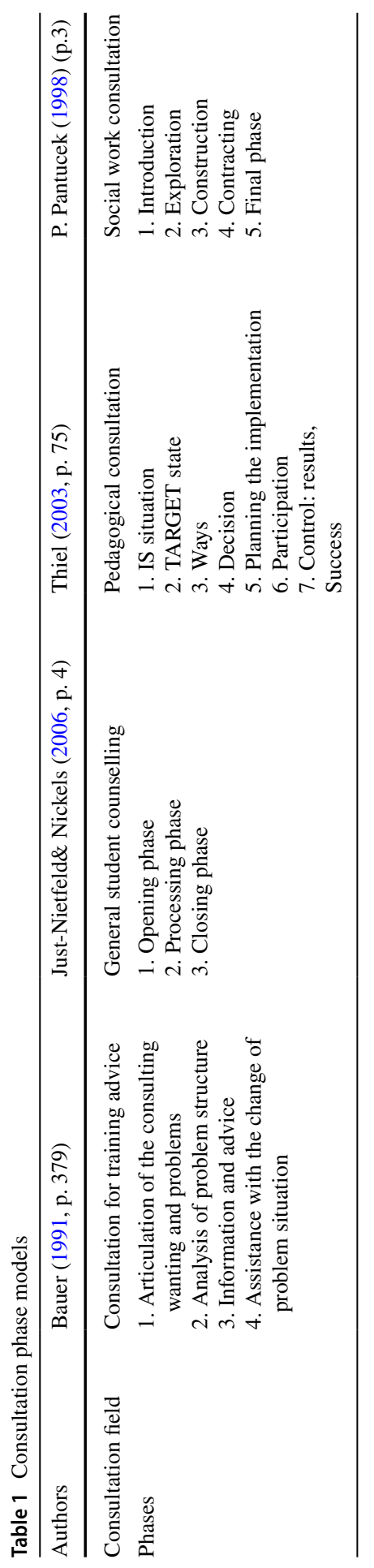


here should be made with a focus on the near future. In the final phase (5), small-talk should be made again, the consultant tries maintaining the relationship and it ends with goodbyes. As in the beginning, this conversation is done in present tense.

All of the models above have in common that there is some kind of introductory phase at the beginning with an opening and a first naming of the client's problems to be solved. But the models differ in terms of the numbers of following phases and in their level of detail. So the next steps of exploring the client's problems and looking for ways to solve these, are different in these models. At the end, most models close with some kind of contracting phase, where the further steps of the clients are planned and the consultation conversation ends.

We base our study on these models and we used them as a framework for our own model development. The model by Pantucek (1998) was especially helpful to make a clear distinction between the phases using the temporal focus. The phases in this model initially seemed to fit well for MLSC consultations and were used as a baseline model for our development.

\section{Research Questions (RQs)}

To gain more knowledge about consulting processes within MLSCs and the interaction between tutors and students, we focussed on the following four research questions concerning the development of a model to describe and analyse MLSCs' consultation dialogs.

\section{MLSC Consultation Model}

$R Q 1$ : Is it possible to identify a model with typical phases within consultations and if so, what characteristics can be found describing these phases?

As we found four models describing consultations from different backgrounds, we tried to adopt some principles from an existing model to set up a new one. This new model aims to be specific for consulting interactions between tutors and students in MLSC's.

\section{MLSC Consultation Dialogs}

$R Q 2:$ How reliably and validly can the phases from the MLSC consultation model be identified?

We use the MLSC consultation model to identify phases within the transcription of different consultations. As a criterion for reliability and construct validity, we expected high consensus (Fleiss' kappa) between the assignments to phases by the different raters.

RQ3: Using the model on hand to analyse the consultations in a MLSC, what describing speech time parameters can be identified?

First, we focus on parameters describing the consultations in terms of speech times by tutors and students. Second, we take a look at different relations of time over different consultation, for example, the time relation of tutors or students talking to the total duration of a consultation. Third, we want to look at the speech times for students and tutors within the proposed MLSC model phases. 
RQ4: Which typical groups or clusters of consultations can be identified?

Once the transcripts of consultation are analysed using our model, we construct diagrams to visualise the phases and speech times of tutors and students. First, we generate diagrams to show interactions using a time continuous scale. Second, we generate diagrams pointing out the total amount of speech time by phases. Then we analyse whether the consultations follow a linear assumed order (phase one to four) or if there are discontinuous orders of phases.

\section{Methods}

In July 2017, data was collected with the help of the 12 tutors of the MLSC at the University of Paderborn (UPB), Germany. All tutors were mathematics majors at UPB and were qualified by a special tutor training for tutorials as well as for work in the MLSC (see above). They mainly gave support for first-year modules (linear algebra and analysis) but also for modules like numerics and stochastics for mathematics students and preservice higher secondary teachers. Due to privacy policy regulations and to ensure the anonymity of students and tutors, we could not record any personal information about their major or progress in their studies (e.g. semester).

Tutors were asked to record three of their conversations with students, where the tutor helped the students with their mathematical problems, mostly tasks from their study assignments (hereafter: MLSC dialog). Tutors used a SmartPen for the consultations. This is a special pen and pad of paper that is linked to a tablet which records the audio of the conversation and a video showing what is written in real time. This resulted in a total of 36 MLSC dialogs with an average length of $15 \mathrm{~min}$.

Tutors as well as the students were informed about the study in advance. Participating in the study was voluntary and the participants gave written consent to the recordings of the consultations.

With the help of other student assistants (SA), the MLSC dialogs were anonymised and transcribed using three columns: time period, speaker (students or tutors) and dialog with text field containing the notes made with the SmartPen. This approach offered an efficient method to categorise the data in the model.

Unfortunately, three of the MLSC dialogs were found to be not useful due to short recordings by accident, missing relevant content or people talking at the same time which led to incomprehensibility of the conversation.

From the resulting 33 MLSC dialogs, 11 were randomly picked for building the model to analyse and answer RQ1. Starting with the models described in the theoretical framework, the important phases were identified and the first three named authors classified the MLSC dialogs into the phases as the model evolved. To validate and extend the communication model of mathematics support in learning centres, we use a special form of the "Qualitative Content Analysis" by Kuckartz (2019), namely the directed content analysis. "The goal of a directed approach to content analysis is to validate or extend conceptually a theoretical framework or theory" (Hsieh \& Shannon 2005, p. 1281). For this approach we concentrated on the model described by Pantucek (1998) mentioned above. We used a stepwise approach and adopted or, where necessary, changed the model and the phase descriptions after analysing and discussing each dialog. For each 
model phase typical actions of tutors and students were identified in discussion processes and added to the model description. Finally, typical (anchor) examples were identified for each phase using the same 11 MLSC dialogs.

The remaining 22 MLSC dialogs were classified into phases using the MLSC consultation model by the first three authors independently. The dialogs were segmented into parts by speakers. Each dialog segment was assigned to a model phase by the raters. Fleiss' kappa was calculated for the independent ratings using SPSS (Version 24) to see the model's fit in individual classification and to check to what extend the raters agreed in their judgement. According to Landis and Koch (1977), kappa values smaller than zero are interpreted as poor agreement between raters, values between 0.01 and 0.20 as slight agreement, values between 0.21 and 0.40 as fair agreement, values between 0.41 and 0.60 as moderate agreement, values between 0.61 and 0.80 as substantial agreement, and values between 0.81 and 1 as almost perfect agreement.

In a second step, the independent ratings were collated into a master classification using a team approach by the raters-whenever there was a difference in classification within the team, it was discussed and a decision was made concerning the fitting phase for the dialog segment. Descriptive parameters for speech times and relationships of the dialogs were calculated using SPSS as well as MS-Excel.

The SA who transcribed the MLSC dialogs also prepared a spreadsheet for each dialog identifying in detail who spoke (tutor or students) and when. Pauses in the dialog were coded, as well as segments that could not be transcribed due to whispering or interrupting noises by others. The master classification phases were also entered into this spreadsheet. Based on these spreadsheets, calculations of descriptive parameters and a python script were made in order to draw diagrams that helped visualise the data.

\section{Results}

We now present the results of the four research questions defined above, starting with the description of the MLSC consultation model as an answer to RQ1, followed by the findings on using the model to analyse MLSC dialogs to answer RQ 2-4.

\section{Results of RQ1}

\section{MLSC Consultation Model}

The MLSC consultation model was designed using 11 MLSC dialogs. In the stepwise approach, the original model by Pantucek (1998) was modified and enhanced trying to achieve best fit on the dialogs and to attain a clear and specific categorisation. In Table 2, the four phases of the MLSC consultation model are presented. Each phase is described by typical actions of students and tutors and has a specific temporal focus which reflects in the tense used by the dialog partners in their communication or the tense they refer to (e.g. former exercise or lecture parts). 
Table 2 MLSC consultation model

\begin{tabular}{|c|c|}
\hline Phases [Temporal Focus] & Description \\
\hline $\begin{array}{l}\text { Clarification Phase } \\
\text { [Present }]\end{array}$ & $\begin{array}{l}\text { In this phase the exercise with which the students are having difficulties and } \\
\text { the relevant mathematical topic are determined } \\
\text { - Students } \\
\text { - name the topic and the problem } \\
\text { - Tutor } \\
\text { ' asks what problem the students would like to solve } \\
\text { Ideally, this phase pins down the topic or exercise to be solved }\end{array}$ \\
\hline $\begin{array}{l}\text { Exploration Phase } \\
\text { [Past }]\end{array}$ & $\begin{array}{l}\text { In the exploration phase, the students' current thoughts in relation to the } \\
\text { exercise are discussed } \\
\text { - Students } \\
\text { 'present their own thoughts. These can include attempts at a solution or } \\
\text { approaches to the problem } \\
\text { - Tutor } \\
\text { o explores the attempts to solve the exercises, the approaches taken or dif- } \\
\text { ficulties students had by actively inquiring, } \\
\text { ogives feedback to the students' initial thoughts } \\
\text { This phase ideally concludes with a concrete identification of the problem } \\
\text { (either by the student or the tutor), which will be worked on the in the next } \\
\text { phase }\end{array}$ \\
\hline $\begin{array}{l}\text { Construction Phase } \\
\text { [Present }]\end{array}$ & $\begin{array}{l}\text { In the construction phase, the problem or exercise is worked on concretely } \\
\text { Either the tutor or the students can lead the conversation } \\
\text { - Students } \\
\text { o discuss the problem with the tutor, } \\
\text { - ask questions, } \\
\text { - listen and answer questions } \\
\text { - Tutor } \\
\text { o gives (detailed) content-related assistance and thematic explanations, } \\
\text { ogives strategic assistance, } \\
\text { - asks the students questions, } \\
\text { - helps by use of a (self-made) example, possibly clarifying what is to be } \\
\text { shown, } \\
\text { - exemplifies the solution with particular numbers, } \\
\text { gives assistance in writing the solution down formally correct } \\
\text { This phase may be concluded with more general issues arising from the } \\
\text { exercise or problem }\end{array}$ \\
\hline $\begin{array}{l}\text { Contracting Phase and } \\
\text { closing remarks } \\
\text { [Present and near } \\
\text { future }]\end{array}$ & $\begin{array}{l}\text { The interaction about the problem or exercise finishes and the discussion ends } \\
\text { - Tutor or students } \\
\text { o summarise the content, help and the options for solving the problem, } \\
\text { - agree how to proceed after the discussion is complete } \\
\text { As a rule, this phase concludes with the students thanking the tutor and saying } \\
\text { goodbye }\end{array}$ \\
\hline
\end{tabular}

The clarification phase at the beginning of an MLSC consultation is used by students and tutors to specify the topic, mathematical problem or exercise students are struggling with (hereafter: exercise). These conversation parts are conducted in present tense. Typically, in this phase students name the exercise or the tutor asks which exercise students would like to solve. This mostly short phase ends with a clear agreement on an exercise to be solved A typical phrase or statement in this phase would be 
"Student: For this task here, we are supposed to show that P [...]" (I16, 00:00-00:07) or "Student: It's about [...] and we are supposed to show that [...]") (I32, 0:10-0.20).

The following exploration phase focuses on past attempts or thoughts of the students to solve the exercise. Mostly the students present their thoughts themselves or the tutor asks the students which attempts they have made in the past. The tutor tries to identify the students' problem by using techniques of actively inquiring and gives feedback to the initial thoughts or attempts of the students. The phase should ideally end up with a clear and concrete identification of the mathematical problem in detail (either by the student or the tutor) to be worked on in the upcoming phase. Examples for this phase are statements of tutors like: "[...] And do you have a guess?" (I43, 0:22-0:23,5) or "You've got it written down correctly" (I16, 02:05-02:10) [...] "But that is not enough this way" (I16, 02:28-02:31). Students used phases like "My problem is, I know [...], but [..] " (I41, 0:32-0:38) or they describe their problems as here "Right, and we have done in this way, that at first we made this intersection, so, we intersected $\mathrm{P}$ with this here. Are all, would all be odd polynomials then? (I16, 01:47-02:05)".

In the construction phase students and tutors work on the exercise or mathematical problem. Ideally, the tutors try to discuss the problem with the students at eye level, the students ask questions and try to listen to the tutor's explanations. The tutor gives adequate content-related assistance and thematic explanations. Furthermore, the tutor helps by giving examples or by clarifying what the student is expected to show. He or she may exemplify the mathematical solution with particular numbers and give assistance in writing the solution down in a formally correct way. Additionally, the tutor can give strategic assistance for the students' learning process, such as hints to the lecture's script or books. Examples of phrases tutors used in this phase are "ok, uhm, now you need to think about [ ...]" (I36, 0:37-0:41) or "Well, if you want to estimate P, then you can [...] take the number of people [...]" (I40, 5:14-5:22) and "Ok, I'll just try to simply explain why it is sensible to do that" (I41, 2:12-2:15). An example for student dialog part of the construction phase is " $\mathrm{f}$ divided by $\mathrm{g}$ ? in $\mathrm{x}$, zero. If they are continuous, right? Wait. $\mathrm{f}$ and $\mathrm{g}$ are continuous. Ah yes. If $g$ of $\mathrm{x}$ is not zero. Ok. Good. [...]" (I44, 3:39,5-4:05,5).The contracting phase and closing remarks form the end of the MLSC consultation. Either the students or the tutor summarizes the content, the hints and the help which was provided. They agree on further steps of the students' work to be done. Typically, this phase and the dialogs ends with the students thanking the tutor and both giving goodbyes. A typical statement of tutors in this phase is for example "From there, you can do it on your own, I think [...]" (I41, 7:02-7:06) and for students "Ok, I'll try it then" (I36, 3:34-3:36) or "Ok, now one needs to show that our sequence is not divergent to plus or minus infinity and but then convergent. I think we can do this" (I18, 11:33-11:46).

\section{Results of RQ2}

To gain knowledge about the reliability of the raters' judgments and validate the MLSC consultation model and the proposed phases, we calculated Fleiss' kappa for the classification of 22 MLSC dialogs by three raters. The dialogs were segmented into parts based on their respective speaker (tutor or student(s)) and pause segments. 
Table 3 Kappa for individual categories (phases) and overall kappa for all segments

\begin{tabular}{llllllll}
\hline $\begin{array}{l}\text { Rating } \\
\text { Category }\end{array}$ & $\begin{array}{l}\text { Conditional } \\
\text { Probability }\end{array}$ & Kappa & $\begin{array}{l}\text { Asymptotic } \\
\text { Standard } \\
\text { Error }\end{array}$ & $\mathrm{Z}$ & P Value & $\begin{array}{l}\text { Lower 95\% } \\
\text { Asymptotic } \\
\text { CI Bound }\end{array}$ & $\begin{array}{l}\text { Upper 95\% } \\
\text { Asymptotic CI } \\
\text { Bound }\end{array}$ \\
\hline 0 & 0.85 & 0.84 & 0.01 & 93.96 & $<0.01$ & 0.82 & 0.86 \\
1 & 0.71 & 0.71 & 0.01 & 78.97 & $<0.01$ & 0.69 & 0.72 \\
2 & 0.76 & 0.72 & 0.01 & 80.94 & $<0.01$ & 0.71 & 0.74 \\
3 & 0.93 & 0.73 & 0.01 & 81.80 & $<0.01$ & 0.71 & 0.75 \\
4 & 0.68 & 0.65 & 0.01 & 73.32 & $<0.01$ & 0.64 & 0.67 \\
Overall & -- & 0.73 & 0.01 & 124.37 & $<0.01$ & 0.72 & 0.74 \\
\hline
\end{tabular}

$\mathrm{N}=4186$ dialog segments; category coding: $0=$ communication not relevant for the consultation, $1=$ clarification phase, $2=$ exploration phase, $3=$ construction phase, $4=$ contracting phase and closing remarks

In total the MLSC dialogs contained 4186 segments with lengths greater than $0.5 \mathrm{~s}$. Each phase of the model was represented by one category (1 to 4). As some of the dialogs contained communication which was not content of the consultation (e.g. talking about or with other students), these parts were classified separately (category $=0$ ).

The results for Fleiss' kappa (c.f. Table 3) indicate over all the categories a substantial coding by the raters with kappa $=0.73$, which is significantly different from coding by chance $(\mathrm{Z}=124.37 ; \mathrm{P}<0.01)$. Kappa values for each category vary between 0.84 (category $=0$ ) and 0.65 (category $=4$ ), being also significantly different to rating by chance $(Z=93.96$ to $73.32, P<0.01)$.

Short statements of either tutors or students and pauses might influence the calculation of kappa in a positive way, because their belonging to a longer dialog phase (f. e. pauses by one speaker within a longer explanation, or short students' statements as "yes" or "hmm"). Therefore, we did the same calculation for segments with a length of greater than $5 \mathrm{~s}(\mathrm{~N}=1061)$, to take a closer look at longer and meaningful segments. These kappa values presented in Table 4 only slightly differ from those presented above. Again, we found the highest kappa value for category $0(0.79)$ and the lowest for category 4 (0.64), all being significantly different from ratings by

Table 4 Kappa for individual categories (phases) and overall kappa for segments longer than $5 \mathrm{~s}$

\begin{tabular}{llllllll}
\hline $\begin{array}{l}\text { Rating } \\
\text { Category }\end{array}$ & $\begin{array}{l}\text { Conditional } \\
\text { Probability }\end{array}$ & Kappa & $\begin{array}{l}\text { Asymptotic } \\
\text { Standard } \\
\text { Error }\end{array}$ & Z & P Value & $\begin{array}{l}\text { Lower 95\% } \\
\text { Asymptotic CI } \\
\text { Bound }\end{array}$ & $\begin{array}{l}\text { Upper 95\% } \\
\text { Asymptotic CI } \\
\text { Bound }\end{array}$ \\
\hline 0 & 0.79 & 0.79 & 0.02 & 44.33 & $<0.01$ & 0.75 & 0.82 \\
1 & 0.67 & 0.66 & 0.02 & 37.45 & $<0.01$ & 0.63 & 0.70 \\
2 & 0.78 & 0.74 & 0.02 & 41.81 & $<0.01$ & 0.71 & 0.78 \\
3 & 0.92 & 0.71 & 0.02 & 39.98 & $<0.01$ & 0.67 & 0.74 \\
4 & 0.67 & 0.64 & 0.02 & 36.27 & $<0.01$ & 0.61 & 0.68 \\
Overall & -- & 0.71 & 0.01 & 56.21 & $<0.01$ & 0.69 & 0.74 \\
\hline
\end{tabular}

$\mathrm{N}=1061$ dialog segments; category coding: $0=$ communication not relevant for the consultation, $1=$ clarification phase, $2=$ exploration phase, $3=$ construction phase, $4=$ contracting phase and closing remarks 
chance $(\mathrm{Z}=44.33$ to $36.27, \mathrm{P}<0.01)$. The overall kappa value is 0.71 and only a little lower than the value calculated with all segments.

\section{Results of RQ3}

In the further analysis of the MLSC dialogs, we looked at general descriptive parameters for the duration of the consultations. In Table 5, we present the results for the speech times of tutors, the sum of students (as in some consultation there was more than one student), and for pauses as well as total values. Means, standard deviation, minimum and maximum values are given in seconds and minutes.

Overall, the 22 MLSC dialogs had an average duration of $15.66 \mathrm{~min}$, but with a fairly high standard deviation of $9.55 \mathrm{~min}$ due to one very short consultation of $1.40 \mathrm{~min}$ and some longer consultations (the longest one took about $35 \mathrm{~min}$ ). The average speech time of tutors in the consultation was $7.18 \mathrm{~min}$, which was only slightly longer than the ones of the students (6.49). In sum the consultations contained 2.07 min of pauses on average, used by tutors or students for thinking or looking up things in their own or lecture scripts. In some interviews, whispering between students could not be transcribed and was coded as pauses as well.

As we see from the descriptive parameters of the MLSC dialogs, there are differences in the duration of the total speech times between tutors and students, we want to take a closer look at the relationships of speech times for all dialogs. In Fig. 1, these are presented as a spider net for time relations of tutors and students respectively to the total net duration (excluding pauses) of a consultation. The original dialog numbers and a mean value are displayed at the outside circle, the percentages for time relationships are displayed on the central axis, ranging from 0 to $90 \%$. The figure shows that two dialogs have higher percentages of above $80 \%$ for the tutors' speech times (No. $20 \& 33$ ). In these consultations, there were only short questions by the students and long explanations by the tutors. On the other hand, there are also two consultations with high percentages of students' speech times (No. $29 \& 37$ ) of more than 70\%. In these two cases, the students presented their thoughts and previous work on the exercises in very much detail.

Table 5 descriptive time parameters for MLSC dialog segments by sum tutors, the sum of students, pauses and in total

\begin{tabular}{|c|c|c|c|c|c|c|c|c|}
\hline \multirow[b]{2}{*}{ Speech times: } & \multicolumn{4}{|c|}{ time in seconds } & \multicolumn{4}{|c|}{ time in minutes } \\
\hline & Mean & SD & Min & $\operatorname{Max}$ & Mean & SD & Min & $\operatorname{Max}$ \\
\hline Sum of Tutors & 431.03 & 316.48 & 41.32 & 1349.80 & 7.18 & 5.27 & 0.69 & 22.50 \\
\hline Sum of students & 389.54 & 260.62 & 42.78 & 1045.80 & 6.49 & 4.34 & 0.71 & 17.43 \\
\hline Sum of pauses & 124.49 & 117.61 & 0.00 & 522.30 & 2.07 & 1.96 & 0.00 & 8.71 \\
\hline Total & 939.40 & 573.01 & 84.10 & 2097.30 & 15.66 & 9.55 & 1.40 & 34.95 \\
\hline
\end{tabular}

$\mathrm{N}=4186$ dialog segments, $S D$ standard deviation, Min minimum, Max maximum 
Fig. 1 Relationship of tutors and students' speech times to total net times of MLSC dialogs

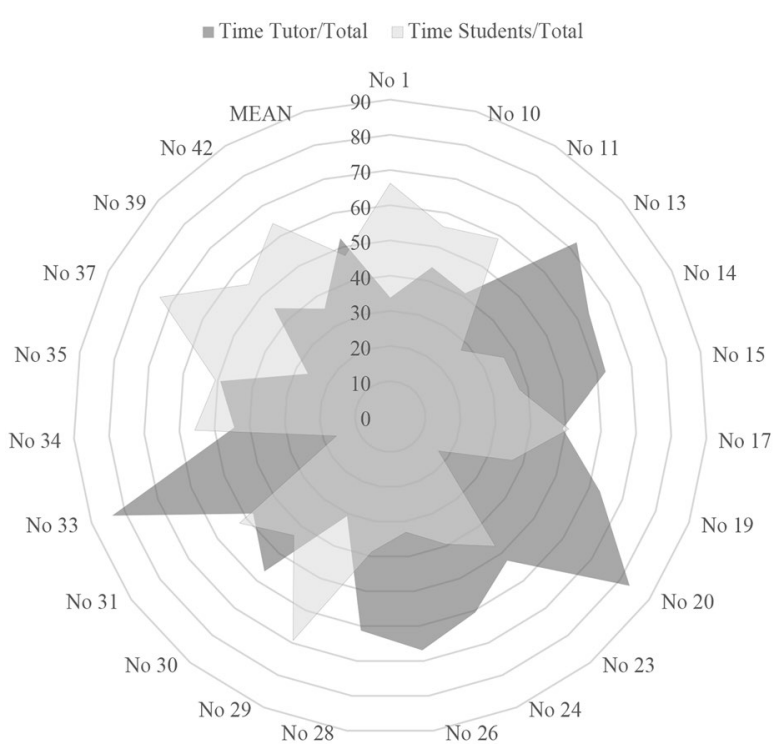

The remaining dialogs are closer to the general mean value of $52.5 \%$ speech time relationship for tutors and $48.5 \%$ for students.

To take a closer look at the dialogs classified in the MLSC model, we present boxplots for the MLSC dialogs' durations by model phases differentiated between tutors' and students' speech times and pauses in Fig. 2. To complete these results, durations for unclassified segments are presented, as well.

$\square$ Tutors $\square$ Students $\triangle$ Pause

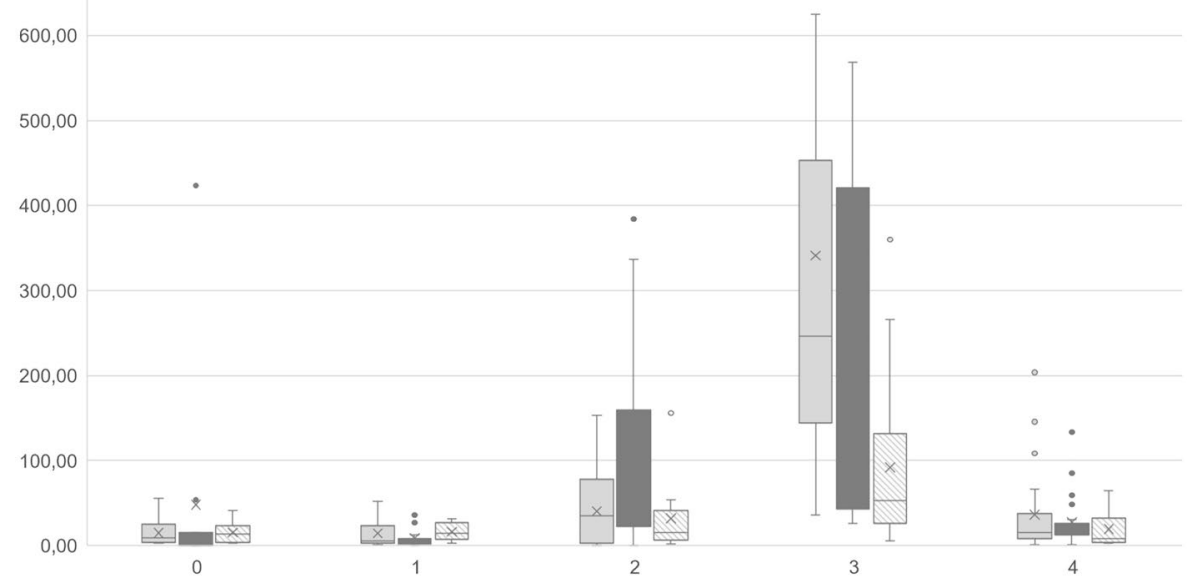

Fig. 2 Boxplots of MLSC dialog duration (in seconds) for tutors' and students' speech times and pauses by MLSC consultation model phases [1 to 4] and not classified segments [0]. Two extreme values of tutors' speech time in phase 3 are suppressed in the boxplot [1201 s.,966 s.] 
We find the longest durations for the construction phase. The mean and median for tutors' speech times in this phase is higher than in the other phases and slightly above those of the students. As this phase by definition is focussed on concrete work on the exercises or solving the students' problems, this fits the model, to be the longest phase. The sum of the pauses also reaches its peak value in this phase, indicating that students or tutors need more time to think or to look up facts in notes or scripts.

In the exploration phase, we find longer speech times of students compared to the tutors. As, by definition, in this phase students present their own thoughts or previous work to the tutor, this also fits the model. The sum of pauses in this phase is smaller compared to the construction phase. In the contracting phase, speech times of tutors are a little higher than those of the students. Compared to phase two and three, the duration of this phase in shorter. The sum of pauses is very low again. By definition, summarizing the contents and agreeing on further working process can be done by either students or tutors. Therefore, these results also fit to the model.

The clarification phase is the shortest phase as tutor's and students' speech times are lower compared to the other phases. By definition, the students name or the tutor asks which problem or exercise they have difficulties with. The short duration of this phase therefore fits to the model, as well.

As mentioned above, some dialog segments were not classified because these communication parts were not content of the consultation. These times are on average very low, with one exception in one MLSC dialog (details see above).

\section{Results of RQ4}

Finally, we present results concerning RQ4, the visualisations of speech interaction between tutors and students and examples for groups of typical consultations we identified.

Out of the 22 MLSC dialogs, we identified 6 dialogs that follow a linear order of the four phases. Students and tutors start in phase 1 (clarification phase) move to phase 2 (exploration phase) then work together in phase 3 (construction phase) and finally end up in phase 4 (contracting phase). Additionally, 5 dialogs showed a chronological order but missed one phase. Mostly in these cases phase 2 was missing as students did not present their previous work or thoughts to the problem (e.g. in cases of basic problems in understanding the exercise) and the tutor started explaining it to the students (phase 3 ) right away.

In addition to the linear MLSC model dialogs, we found 11 dialogs following a nonlinear order of phases. In these dialogs, a speaker switched back to an earlier phase. For example, a tutor switched back from phase 2 where the student explained his thoughts on the problem to phase 1 to clarify the exercise or a student hold on to his previous workouts within the construction phase, getting back from phase 3 to 2. We also found cases where students and tutors were summing up the content in phase 4 and it became obvious that the student needed another little help moving back to phase 3 . 
Tutoring Consultation Number 026
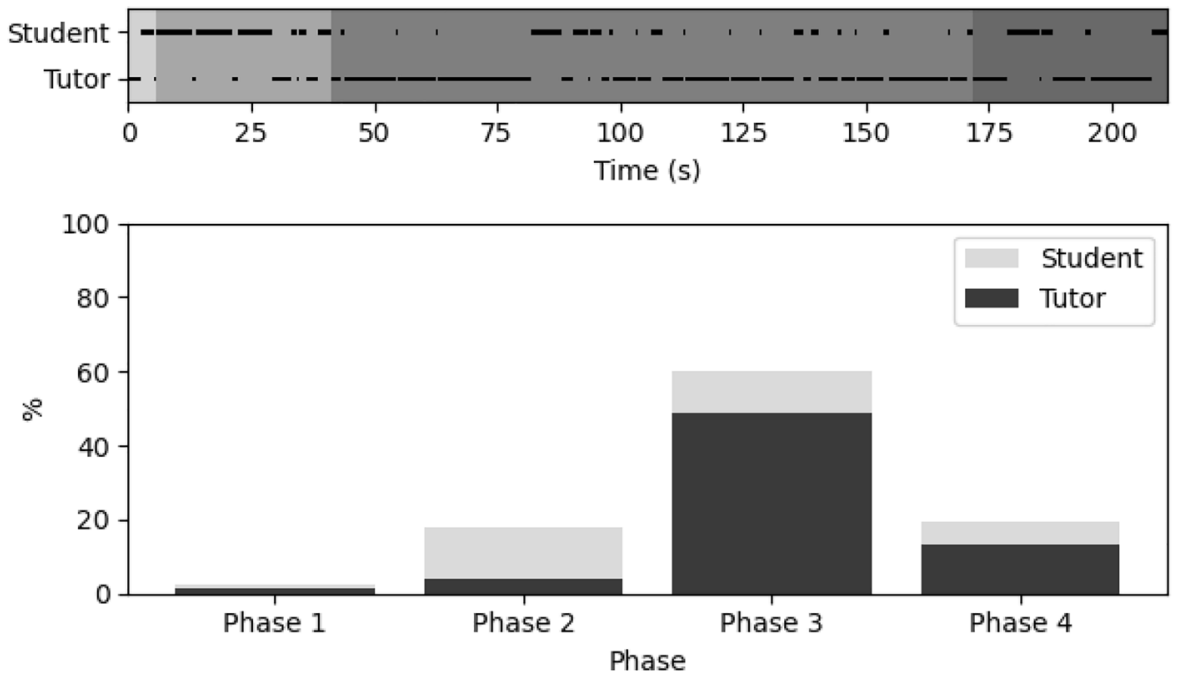

Fig. 3 Interactions of student and tutor in a typical linear MLSC model dialog

As an example, for the group of consultations with linear order, in Fig. 3 we present the visualisations of speech interactions of the MLSC dialog No 29. At the top of the figure, we present a continuous time line (in seconds) and speech times of either tutor or student(s) are indicated by a black line. Thus, this line shows who is talking in the consultation over time. To enhance visibility of the figure, pauses and unclassified segments (category 0) are not presented and in case of dialogs with more than one student, these are represented by one student line only. In the background of this figure, the MLSC model phases are coloured in different shades of grey from light grey (phase 1) to dark grey (phase 4). In the bottom part of the figure, we present a bar graph with the percentages of speech times for tutor and student for the four MLSC model phases.

The interaction in MLSC dialog No 29 (Fig. 3) starts with the tutor in phase 1 asking the student what his or her question is, and he/she answers and names the problem. In phase 2 , the student presents the previous work and thoughts on the problem and the tutor gives a short feedback. Phase 3 starts with a longer explanation of the tutor on the problem and the students give short comments. Later on in this phase, the student asks questions in between the tutor's explanations. At the end of the consultation in phase 4, the tutor and student agree upon the further proceeding for solving the exercise and the student thanks the tutor for the provided help.

An example for a nonlinear MLSC dialog is presented in Fig. 4. As typical for MLSC dialogs, the student and tutor start in phase 1, talking about the problem to be solved or the exercise. In phase 2, the student presents his/her previous thoughts and elaborations. Next, the tutor and student start working together on the problem/exercise in phase 3 but the tutor and student get back to previous content of the lectures 

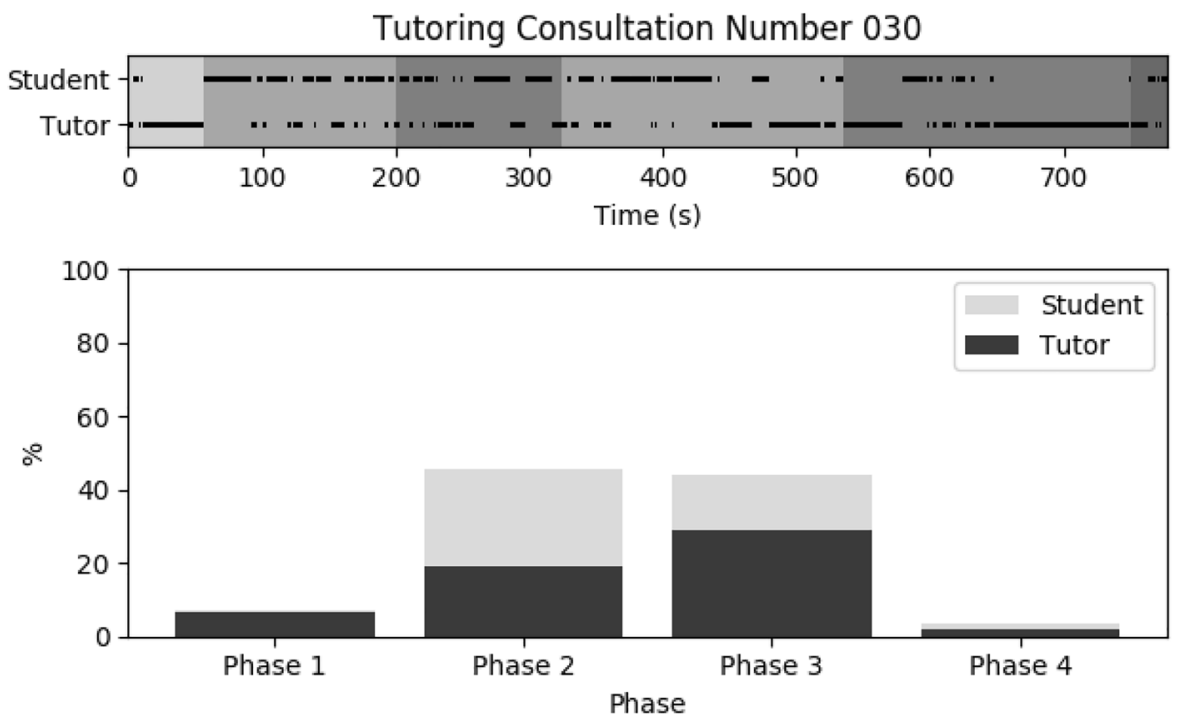

Fig. 4 Interactions of student and tutor in a typical nonlinear MLSC model dialog

(initiated by the tutors) so they switch back to phase 2. After this, the tutor and student continue in phase 3 and end up in phase 4.

The bar graph to the MLSC dialog No. 26 in Fig. 4 summarizes the speech times of tutor and student in the MLSC model phases. Phase 1 is very short (6 s) with about $3 \%$ of the total consultation duration $(212 \mathrm{~s})$. In phase 2 , the student has a longer speech time than the tutor and in sum this phase lasts $36 \mathrm{~s}(17 \%$ of the total consultation). In phase 3, the tutor explains for longer periods of time, totalling up to $50 \%$ of the whole consultation. Together with the student's speech time, phase 3 has a total duration of $130 \mathrm{~s}(61 \%)$. Phase 4 at the end of the consultation, lasts $40 \mathrm{~s}$ (19\%) with most of the speech time belonging to the tutor.

\section{Summary and Discussion}

As an answer to RQ1, we can sum up that we did identify four different phases which might be typical for consultations at MLSCs and we described the characteristics of these phases. In addition to the work of Schoenfeld $(1992,2010)$ and Ball et al. (2008), our model offers a new differentiation between exploration and construction phases for tutoring consultations in the context of MLSC. As students come to the MLSC because of specific mathematical demands for support, mostly for weekly assignments, the interaction between student and tutor can also be seen as a shared problem-solving process. Therefore, our MLSC phase model shows some structural parallels to Carlson and Bloom's (2005) problem solving cycle in mathematics: (1) Orienting, (2) Planning, (3) Executing and (4) Checking, but the phase descriptions of tutors and students' actions are different. Compared to Graesser et al. 
(1995) five-step dialog frame, our construction phase shows some parallels which might be worth further investigation.

Compared to the model by Pantucek (1998) that we based our model on, the MLSC model first of all differs in the content it is used for. Whereas Pantucek (1998) developed his model for social work and social consultation situations, we adapted the model to mathematical consultation situations. In the MLSC model, the first four phases are similar to Pantucek's (1998) model. Especially the temporal focus within the phases was consistent. But we could not find a separate fifth phase as in Pantucek's (1998) model. Some aspects, as closing remarks or little small talk at the end (students thanking the tutor for help) were included by us in phase four (Contracting Phase and closing remarks).

To answer RQ2, we calculated Fleiss' kappa for ratings of MLSC dialog segments by different raters. The medium to high kappa values with scores above 0.60 indicate a substantial agreement on the coding of dialog segments to the model phases (c.f. Landis \& Koch, 1977; Zapf et al., 2016). The overall kappa indicates an acceptable reliability independently from the length of the segments been coded (0.73 vs 0.71 ). The calculated kappa scores for the four model phases focussing on segments with a length longer than $5 \mathrm{~s}$ were also substantial (variation between 0.64 and 0.74). Theses scores indicate that the model phases were identified reliably and specifically. We also interpret these scores as an indication for construct validity of our model since each phase of the model was coded substantially. We have to admit though, that no external raters were used for the coding of segments to the model phases. The kappa scores might be biased due to deeper understanding of the model by the authors and results might be lower if outside raters would be trained to categorise dialogs with the model.

To answer RQ3, we looked at different descriptive parameters for the duration of MLSC consultations and speech time relationships. We found a great variation of MLSC consultation times and in the relationships of speech times but these were mainly caused by extreme values. In general, the consultations can be meaningfully described by the mean values for speech times and durations of the dialogs. The relationships of speech times indicated that four consultations were dominated either by long speeches of students or tutors. Overall, the values for speech time relationships seem to equal out and the presented means are representative for the remaining consultations.

The question here is where the variability comes from. If students need different kinds of support, different proportions of the conversations could be justified. In this respect, the question is raised whether there can be basic recommendations for speech times. For example, students might have difficulties in keeping everything in mind and it might be helpful for them to reproduce intermediate results in their own words. Consultations with relatively short student speech times indicate that this might not have happened and tutors might have acted out in their explaining and giving inputs to students without a reflection process and a reproduction of results by the students.

It is also noticeable that the phases 2 and 3 take up most of the time of a support session. The consultation processes were very focussed on discussing and solving concrete problems. In the mean values we found a shift of the speech time in phase 2 
(higher for students) to phase 3 (higher for tutors). This might indicate that in phase 2 students present their previous work or thoughts on the problem in detail and in phase 3 the tutor gives detailed explanations. If this fact can be replicated by others, it would be worthwhile to further investigate patterns within these phases. In the future, it should also be investigated to what extent metacognition also takes place, which could rather be located in phases 1 and 4. According to Polya (1945), reflecting on the solution is particularly important in problem solving. Students might only want to have a solution for their concrete problem (or exercise) and not want to take up their time or the time of the tutors for further thoughts and reflections.

To answer RQ 4, we built diagrams for all dialogs and analysed these concerning their linearity or nonlinearity in the MLSC model phases. We found half of the dialogs following a linear order of phases although in five dialogs a phase was missing. The other half had a nonlinear order of phases, characterized by some switching back to earlier phases by one of the speakers.

The results make it clear that the model describes the process only ideally, but that deviations are also possible in real processes. This seeming misfit is not wrong at all. "Precisely because consulting typically proceeds in cyclical spirals, i.e., consultants and those seeking advice proceed together but at the same time jump back and forth between different phases, it is important for consultants to have an awareness of different consultation progressions and to be able to retrieve suitable action strategies appropriate to the situation" (Gieseke et al., 2007, p.35, our translation).

\section{Further Research}

The presented model breaks down consultations into four phases. Based on this model, we should conduct empirical research to determine what goals and strategies students and tutors have in each phase and how consultations were made that were experienced as particularly helpful.

In addition, we should discuss normative models including typical goals and strategies that we may recommend, particularly with regard to training tutors. Considering normative models, it could also be useful to expand processes to include aspects that have hardly ever occurred before. For example, explicit time could be given for reflection on a successful problem-solving process. Additionally, the phase model and the presented phases can be analysed in depth for mathematical content-specific relations or patterns, which could be arranged by a balanced research design. A deeper subject-related analysis with special methods of mathematical discourse analysis could provide further insights in future studies.

The model we have developed so far might also be improved. We welcome researchers to replicate our study at other MLSCs and to identify necessary model changes or enhancements. In particular, it would be very interesting to see if the model can be replicated for different (service) mathematic study programs and if there might be mathematical content-specific patterns. Additionally, it could be beneficial to analyse differences between consultations given by staff members and those given by tutors, as well as to focus on specific mathematical content of consultations. 


\section{Practical Consequences}

The model can help in creating transparency about what happens in a support session. This would allow students to better adjust and prepare. They might thus be encouraged a little bit more to seek help. Similarly, tutors could use the model to better prepare for their work, anticipate phases and set goals for their moderation. That should take the cognitive load off them and give them structure. The model could also be used in tutor trainings to more explicitly discuss which situations, goals, and strategies might arise in support sessions. Further more the use of the model to analyse support sessions, as we presented above, gives leaders or mangers of a MLSCs insights and detailed information on the concrete interaction between student and tutors. These results can be additionally used for tutor trainings.

\section{Limitations}

This study is an explorative analysis at just one German MLSC with a limited number of dialogs being analysed. The MLSC, in which the dialogs have been recorded, focusses on consultations for students studying mathematics or mathematics education, but this information was not recorded. Following the privacy policy regulations and to ensure the anonymity of students and tutors, we could not record any personal information about their major or progress in their studies (e.g. semester). As tutors in the MLSC also work in the tutorials, we can assume that students and tutors were familiar with each other, but we did not record this fact, which might have had an influence on the interactions. The raters who coded dialog segments were involved in the model development and therefore the interrater-reliability may be biased. The MLSC model needs to be validated nationally and internationally as well as in MLSCs with a focus on other students having mathematics as an additional subject (e.g. engineering or natural sciences studies).

Authors' Contributions All authors contributed to the study conception and design or in the data analysis and writing processes. Material preparation, data collection and analysis were performed by Mirko Schürmann, Anja Panse and Zain Shaikh. The first draft of the manuscript was written by Mirko Schürmann and all authors commented on previous versions of the manuscript. All authors read and approved the final manuscript, except Zain Shaikh who left the university sector.

Funding Open Access funding enabled and organized by Projekt DEAL. The study was conducted within the WiGeMath project. It was funded by the German Federal Ministry of Education and Research (BMBF) from 2016 through 2018, grant identifiers 01PB14015A and 01PB14015B and from 2018 through 2020, grant identifiers 01PB18015A and 01PB18015B.

\section{Declarations}

Conflict of Interest We confirm that there are no relevant financial or non-financial competing interests.

Open Access This article is licensed under a Creative Commons Attribution 4.0 International License, which permits use, sharing, adaptation, distribution and reproduction in any medium or format, as long as you give appropriate credit to the original author(s) and the source, provide a link to the Creative 
Commons licence, and indicate if changes were made. The images or other third party material in this article are included in the article's Creative Commons licence, unless indicated otherwise in a credit line to the material. If material is not included in the article's Creative Commons licence and your intended use is not permitted by statutory regulation or exceeds the permitted use, you will need to obtain permission directly from the copyright holder. To view a copy of this licence, visit http://creativecommons.org/ licenses/by/4.0/.

\section{References}

Aebli, H. (2006). Zwölf Grundformen des Lehrens. Eine Allgemeine Didaktik auf psychologischer Grundlage. Medien und Inhalte didaktischer Kommunikation, der Lernzyklus. Stuttgart: Klett-Cotta.

Ball, D. L., Thames, M. H., Phelps, G. (2008). Content Knowledge for Teaching What Makes It Special? Journal of Teacher Education, 59. https://doi.org/10.1177/0022487108324554

Bauer, G. (1991). Weiterbildungsberatung. Mitteilungen der Arbeitsmarkt- und Berufsforschung, 24 (2), 375-384. http://doku.iab.de/mittab/1991/1991_2_MittAB_Bauer.pdf. Accessed 15.05.2019.

Bausch, I., Biehler, R., Bruder, R., Fischer, P. R., Hochmuth, R., Koepf, W., Schreiber, S. \& Wassong, T. (Ed.). (2014). Mathematische Vor- und Brückenkurse. Springer Fachmedien Wiesbaden.

Biehler, R., Lankeit, E., Neuhaus, S., Hochmuth, R., Kuklinski, C., Leis, E., Liebendörfer, M., Schaper, N., \& Schürmann, M. (2018). Different goals for pre-university mathematical bridging courses Comparative evaluations, instruments and selected results. In V. Durand-Guerrier, R. Hochmuth, S. Goodchild, \& N. M. Hogstad (Ed.), PROCEEDINGS of INDRUM 2018 Second conference of the International Network for Didactic Research in University Mathematics (p. 467-476). University of Agder and INDRUM: Kristiansand, Norway.

Burks, L., \& James, J. (2019). Mathematical knowledge for tutoring undergraduate mathematics. In A. Weinberg, D. Moore-Russo, H. Soto \& M. Wawro (Ed.), Proceedings of the $22^{\text {nd }}$ Annual Conference of Research in Undergraduate Mathematics Education, (p. 731-740). Oklahoma City, OK. http://sigmaa.maa.org/rume/RUME22_Proceedings.pdf. Accessed 07.07.2021.

Carlson, M. P., \& Bloom, I. (2005). The Cyclic Nature of Problem Solving: An Emergent Multidimensional Problem-Solving Framework. Educational Studies in Mathematics, 58, 45-75. https://doi.org/ 10.1007/s10649-005-0808-x

Croft, T., \& Grove, M. J. (2011). Tutoring in a Mathematics Support Centre: A Guide for Postgraduate Students. Available at: http://www.mathcentre.ac.uk/resources/uploaded/46836-tutoring-in-mscweb.pdf. Accessed 15.05.2019.

Croft, T., \& Grove, M. J. (2016). Mathematics and statistics support centres: Resources for training postgraduates and others who work in them. MSOR Connections, 14(3), 3-13. https://doi.org/10.21100/ msor.v14i3.305

Croft, T., Lawson, D., Hawkes, T., Grove, M., Bowers, D., \& Petrie, M. (2015). Sigma-a network working. Mathematics Today, 50(1), 36-40.

Dieter, M., \& Törner, G. (2012). Vier von fünf geben auf: Studienabbruch und Fachwechsel in der Mathematik. Forschung \& Lehre, 12(10), 826-827.

Fischer, P. (2014). Mathematische Vorkurse im Blended Learning Format - Konstruktion, Implementation und wissenschaftliche Evaluation. Springer Spektrum.

Fleischmann, Y. \& Kempen, L. (in press). Wiederholung von Schulmathematik oder Antizipation von Studieninhalten? - Adressatenspezifische Ausgestaltung mathematischer Vorkurse am Beispiel der Paderborner Vorkursvarianten. In: R. Hochmuth, R. Biehler, M. Liebendörfer, \& N. Schaper (Ed.), Unterstützungsmaßnahmen in mathematikbezogenen Studiengängen - Eine anwendungsorientierte Darstellung verschiedener Konzepte, Praxisbeispiele und Untersuchungsergebnisse. Wiesbaden: Springer Fachmedien.

Frischemeier, D., Panse, A., \& Pecher, T. (2016). Schwierigkeiten von Studienanfängern bei der Bearbeitung mathematischer Übungsaufgaben. In: Hoppenbrock A., Biehler R., Hochmuth R. \& Rück HG. (Ed.) Lehren und Lernen von Mathematik in der Studieneingangsphase. Konzepte und Studien zur Hochschuldidaktik und Lehrerbildung Mathematik. Springer Spektrum: Wiesbaden.

Greefrath, G., \& Vorhölter, K. (2016). Teaching and Learning Mathematical Modelling: Approaches and Developments from German Speaking Countries. In: Teaching and Learning Mathematical Modelling. ICME-13 Topical Surveys. Springer, Cham. https://doi.org/10.1007/978-3-319-45004-9_1 
Gieseke, W., Käpplinger, B., \& Otto, S. (2007). Prozessverläufe in der Beratung analysieren - Ein Desiderat. Begründung und Entwicklung eines Forschungsdesigns. REPORT (30) 1/2007. http://www.diebonn.de/doks/gieseke0702.pdf. Accessed 18.01.2018.

Gieseke, W., \& Stimm, M. (2016). Praktiken der professionellen Bildungsberatung - Innensichten auf die Entscheidungsfindung im Beratungsprozess. Springer VS.

Göller, R. (2020). Selbstreguliertes Lernen im Mathematikstudium. Springer Fachmedien Wiesbaden. https://doi.org/10.1007/978-3-658-28681-1

Graesser, A. C., Person, N. K., \& Magliano, J. P. (1995). Collaborative dialogue patterns in naturalistic one-to-one tutoring. Applied Cognitive Psychology, 9(6), 495-522. https://doi.org/10.1002/acp. 2350090604

Grove, M., \& Croft, T. (2019). Learning to Be a Postgraduate Tutor in a Mathematics Support Centre. International Journal of Research in Undergraduate Mathematics Education, 5(2), 228-266. https:// doi.org/10.1007/s40753-019-00091-8

Grove, M. J., Croft, A. C., Lawson, D. A., \& Petrie, M. (2019a). Community perspectives of mathematics and statistics support in higher education: The role of the staff member. Teaching Mathematics and Its Applications: An International Journal of the IMA, 38, 43-59. https://doi.org/10.1093/teamat/ hrx017

Grove, M., Croft, T., \& Lawson, D. (2019b). The extent and uptake of mathematics support in higher education: Results from the 2018 survey. Teaching Mathematics and Its Applications: An International Journal of the IMA, 00, 1-19. https://doi.org/10.1093/teamat/hrz009

Grove, M., \& Mac an Bhaird, C., \& O'Sullivan, C. (2019). Professional development opportunities for tutors of mathematics learning support. MSOR Connections, 18(1), 4-15. https://doi.org/10.21100/ msor.v18i1.1021.

Heublein, U., Hutzsch, C., Schreiber, J., Sommer, D., \& Besuch, G. (2010). Ursachen des Studienabbruchs in Bachelor-und in herkömmlichen Studiengängen. HIS Hochschul-Informations-System GmbH. http://www.his-hf.de/pdf/pub_fh/fh-201002.pdf . Accessed 15.05.2019.

Heublein, U., \& Schmelzer, R. (2018). Die Entwicklung der Studienabbruchquoten an den deutschen Hochschulen. Hannover: DZHW. https://idw-online.de/en/attachmentdata66127.pdf. Accessed 15.05.2019.

Hochmuth, R., Biehler, R., Schaper, N., Kuklinski, C., Lankeit, E., Leis, E., Liebendörfer, M., \& Schürmann, M. (2018). Wirkung und Gelingensbedingungen von Unterstützungsmaßnahmen für mathematikbezogenes Lernen in der Studieneingangsphase (Abschlussbericht). Leibniz Universität Hannover. https://doi.org/10.2314/KXP:1689534117

Hsieh, H.-F., \& Shannon, S. E. (2005). Three Approaches to Qualitative Content Analysis. Qualitative Health Research, 15(9), 1277-1288. https://doi.org/10.1177/1049732305276687

Just-Nietfeld, J., \& Nickels, B. (2006). Basics der Allgemeinen Studienberatung - Eine Positionsbestimmung aus niedersächsischer Perspektive. Zeitschrift Für Beratung Und Studium, 1(1), $2-9$.

Johnson, E., \& Hanson, K. (2015). Academic and social supports. In D. Bressoud, V. Mesa, \& C. Rasmussen (Ed.), Insights and recommendations from the MAA national study of college calculus (p. 69-82). MAA Press.

Kaiser, G., \& Stender, P. (2013). Complex Modelling Problems in Co-operative, Self-Directed Learning Environments. In: Stillman G., Kaiser G., Blum W., Brown J. (Ed.) Teaching Mathematical Modelling: Connecting to Research and Practice. International Perspectives on the Teaching and Learning of Mathematical Modelling. Springer, Dordrecht. https://doi.org/10.1007/978-94-007-6540-5_ 23

Kuckartz, U. (2019). Qualitative Content Analysis: From Kracauer's Beginnings to Today's Challenges. Forum: Qualitative Social Research, 20(3), Art. 12. https://doi.org/10.17169/fqs-20.3.3370

Landis, J., \& Koch, G. (1977). The measurement of observer agreement for categorical data. Biometrics. 33 (1),159-174. https://www.jstor.org/stable/2529310. Accessed 13.12.2020.

Lawson, D., Croft, T., \& Halpin, M. (2003). Good Practice in the Provision of Mathematics Support Centres. http://www.mathcentre.ac.uk/resources/guides/goodpractice2E.pdf. Accessed 10.12.2019.

Lawson, D., Grove, M., \& Croft, T. (2019). The evolution of mathematics support: A literature review. International Journal of Mathematical Education in Science and Technology. https://doi.org/10. 1080/0020739X.2019.1662120

Liebendörfer, M., \& Göller, R. (2016). Abschreiben-Ein Problem in mathematischen Lehrveranstaltungen? In W. Paravicini \& J. Schnieder (Ed.), Hanse-Kolloquium zur Hochschuldidaktik der Mathematik 2014 Beiträge zum gleichnamigen Symposium am 7. \& 8. November 2014 an der Westfälischen Wilhelms-Universität Münster (p. 119-141). WTM-Verlag für wissenschaftliche Texte und Medien. 
Liebendörfer, M., \& Hochmuth, R. (2017). Perceived competence and incompetence in the first year of mathematics studies: Forms and situations. In R. Göller, R. Biehler, R. Hochmuth, \& H.-G. Rück (Ed.), Didactics of Mathematics in Higher Education as a Scientific Discipline-Conference Proceedings (p. 286-293). Universität Kassel. https://kobra.bibliothek.uni-kassel.de/bitstream/urn:nbn: de:hebis:34-2016041950121/5/khdm_report_17_05.pdf

MacDonald, R. B. (2000). The master tutor: A guidebook for more effective tutoring. Williamsville, N.Y: Cambridge Stratford Study Skills Institute.

Matthews, J., Croft, T., Waller, D., \& Lawson, D. (2013). Evaluation of mathematics support centres: A literature review. Teaching Mathematics and its Applications, 32(4), 173-190. https://doi.org/10. 1093/teamat/hr

Milfeit, L., Krüger, K., \& Frischemeier, D. (2018). Lernzentrum Mathetreff. In: Riegraf, B., Meister, D., Reinhold, P. Schaper, N. \& Temps, T. (Ed.): Heterogenität als Chance: Bilanz und Perspektiven des Qualitätspakt Lehre-Projekts an der Universität Paderborn, p. 96-98. https://doi.org/10.17619/ UNIPB/1-336

Mills, M., Rickard, B., \& Guest, B. (2020). Survey of mathematics tutoring centres in the USA. International Journal of Mathematical Education in Science and Technology. https://doi.org/10.1080/ 0020739X.2020.1798525

O’Sullivan, C., Mac an Bhaird, C., Fitzmaurice, O., \& Ní Fhloinn, E. (2014). An Irish mathematics support network (IMLSN) report on student evaluation of mathematics support: Insights from a large scale multi-institutional survey. Limerick: National Centre for Excellence in Mathematics and Science Teaching and Learning.

Panse, A., Shaik, Z., Krüger, K., Biehler, R., \& Hilgert, J. (2018). Unterstützung im Mathematikstudium: Lernzentren und Brückenveranstaltungen. In: Riegraf, B., Meister, D., Reinhold, P. Schaper, N. \& Temps, T. (Ed.): Heterogenität als Chance: Bilanz und Perspektiven des Qualitätspakt Lehre-Projekts an der Universität Paderborn, p. 92-95. https://doi.org/10.17619/UNIPB/1-336

Pantucek, P. (1998). Techniken der Gesprächsführung. http://www.pantucek.com/seminare/200709avalon/ gespraechskript.pdf. Accessed 12.02.2017.

Pfeiffer, K., Cronin, A., \& Mac an Bhaird, C. (2016). The key role of tutors in mathematics learning support - a report of the 10th annual IMLSN workshop. MSOR Connections, 15(1), 39-46. https://doi.org/10.21100/msor.v15i1.367.

Polya, G. (1945). How to solve it: A new aspect of mathematical method. Princeton University Press Princeton.

Püschl, J. (2017). Identifying discussion patterns of teaching assistants in mathematical tutorials in Germany. CERME 10, Dublin. https://keynote.conference-services.net/resources/444/5118/pdf/CERME10_0148. pdf. Accessed 05.07.2021.

Püschl, J. (2019). Kriterien guter Mathematikübungen - Potentiale und Grenzen in der Aus- und Weiterbildung von studentischen TutorInnen. Springer Spektrum.

Schoenfeld, A. H., Gamoran, M., Kessel, C., \& Leonard, M. (1992). Toward a comprehensive model of human tutoring in complex subject matter domains. The Journal of Mathematical Behavior, 11(4), 293-319.

Schoenfeld, A. H. (2010). How we think: A theory of goal-oriented decision making and its educational applications. Routledge. https://doi.org/10.4324/9780203843000

Schoenfeld, A.H. (2015). How We Think: A Theory of Human Decision-Making, with a Focus on Teaching. In: Cho S. (Ed.) The Proceedings of the 12th International Congress on Mathematical Education. Springer, Cham. https://doi.org/10.1007/978-3-319-12688-3_16

Schürmann, M., Gildehaus, L., Liebendörfer, M., Schaper, N., Biehler, R., Hochmuth, R., Kuklinski, C., \& Lankeit, E. (2020). Mathematics learning support centres in Germany-An overview. Teaching Mathematics and Its Applications: An International Journal of the IMA, 00, 1-15. https://doi.org/ 10.1093/teamat/hraa007

Thiel, H.-U. (2003). Phasen des Beratungsprozesses. In: Krause, C., Fittkau, B., Fuhr, R \& Thiel H.-U. (Ed.): Pädagogische Beratung - Grundlagen und Praxisanwendung. Paderborn: UTB, 73-84.

Walsh, R. (2017). A case study of pedagogy of mathematics support tutors without a background in mathematics education. International Journal of Mathematical Education in Science and Technology, 48(1), 67-82. https://doi.org/10.1080/0020739X.2016.1220028

Wlassak, L. (2018). Offener Matheraum - Ein Unterstützungsangebot zum effektiveren Lernen mathematischer Arbeitstechniken. In: Fachgruppe Didaktik der Mathematik der Universität Paderborn (Ed.). Beiträge zum Mathematikunterricht 2018. Münster: WTM-Verlag. https://doi.org/10.17877/ DE290R-19788 
Zapf, A., Castell, S., Morawietz, L., \& Krach, A. (2016). Measuring inter-rater reliability for nominal data - which coefficients and confidence intervals are appropriate?. BMC Med Res Methodol 16, 93 (2016). https://doi.org/10.1186/s12874-016-0200-9

Zech, F. (1996). Grundkurs Mathematikdidaktik: Theoretische und praktische Anleitungen für das Lehren und Lernen von Mathematik. Beltz.

Publisher's Note Springer Nature remains neutral with regard to jurisdictional claims in published maps and institutional affiliations. 